\title{
MtNIP5;1, a novel Medicago truncatula boron diffusion facilitator induced under deficiency
}

\author{
Sara Granado-Rodríguez, Luis Bolaños and Maria Reguera* (i)
}

\begin{abstract}
Background: Legumes comprise important crops that offer major agronomic benefits, including the capacity of establishing symbiosis with rhizobia, fixing atmospheric $N_{2}$. It has been proven that legumes are particularly susceptible to boron (B) stress, which leads to important yield penalties. Boron (B) deficiency or toxicity in plants causes the inhibition of growth and an altered development. Under such conditions, the participation of two distinct protein families (the major intrinsic protein family MIP and the Boron transporter family BOR) is required to minimize detrimental effects caused by B stress. However, in legumes, little is known about the transport mechanisms responsible for $B$ uptake and distribution, especially under deficiency.

Results: A Medicago truncatula protein, MtNIP5;1 (Medtr1g097840) (homologous to the Arabidopsis thaliana AtNIP5; 1) was identified as a novel legume B transporter involved in B uptake under deficiency. Further analyses revealed that this M. truncatula aquaporin expression was boron-regulated in roots, being induced under deficiency and repressed under toxicity. It localizes at the plasma membrane of root epidermal cells and in nodules, where B plays pivotal roles in symbiosis. Furthermore, the partial complementation of the nip5;1-1 A. thaliana mutant phenotype under B deficiency supports a functional role of MtNIP5;1 as a B transporter in this legume model plant.
\end{abstract}

Conclusions: The results here presented support a functional role of MtNIP5;1 in B uptake under deficiency and provides new insights into B transport mechanisms in legume species.

Keywords: Boron deficiency, Medicago truncatula, Aquaporins, MtNIP5;1, Boron transport, Legumes

\section{Background}

Boron (B) is an essential micronutrient for plants as it plays a structural role in plant cell walls, crosslinking two pectin polysaccharides rhamnogalacturonan-II [1, 2]. When B concentrations are below optimum, Bdeficiency symptoms appear and include the inhibition of root elongation and a reduced leaf expansion and fertility, which results in substantial agronomical losses around the world [3-5].

\footnotetext{
* Correspondence: maria.reguera@uam.es

Departamento de Biología, Universidad Autónoma de Madrid, c/Darwin 2, Campus de Cantoblanco, 28049 Madrid, Spain
}

In soils, $\mathrm{B}$ is mainly found as uncharged boric acid [B $\left.(\mathrm{OH})_{3}\right]\left(\mathrm{Ka}=5.80 \times 10-10\right.$ at $\left.25^{\circ} \mathrm{C}(\mathrm{pKa}=9.24)\right)[6]$. At optimal concentrations, $\mathrm{B}$ enters the plant through passive diffusion. However, under deficiency, B is transported into and within the plant by the coordinated action of proteins that belong to two protein families: the major intrinsic protein family MIP and the Boron transporter family BOR [7-10]. MIPs are a superfamily of aquaporins made up of several subfamilies, including the nodulin-26-like intrinsic proteins (NIPs) [11], which are permeable channels to small solutes including $[\mathrm{B}$ $\left.(\mathrm{OH})_{3}\right][12-16]$.

In plants, the best characterized NIP protein described as a B facilitator transporter is the Arabidopsis thaliana

\section{$\triangle B M C$}

(c) The Author(s). 2020 Open Access This article is licensed under a Creative Commons Attribution 4.0 International License, which permits use, sharing, adaptation, distribution and reproduction in any medium or format, as long as you give appropriate credit to the original author(s) and the source, provide a link to the Creative Commons licence, and indicate if changes were made. The images or other third party material in this article are included in the article's Creative Commons licence, unless indicated otherwise in a credit line to the material. If material is not included in the article's Creative Commons licence and your intended use is not permitted by statutory regulation or exceeds the permitted use, you will need to obtain permission directly from the copyright holder. To view a copy of this licence, visit http://creativecommons.org/licenses/by/4.0/ The Creative Commons Public Domain Dedication waiver (http://creativecommons.org/publicdomain/zero/1.0/) applies to the data made available in this article, unless otherwise stated in a credit line to the data. 
(L.) Heynh. NIP5;1, (AtNIP5;1), a cell membrane channel permeable to water, urea and $\left[\mathrm{B}(\mathrm{OH})_{3}\right]$ [17]. AtNIP5; 1 is found in epidermal cells of roots, and its transcripts are up-regulated under low $\mathrm{B}$ conditions, increasing $B$ permeability and maximizing $B$ uptake from B-deficient soils [15].

On the other hand, BOR proteins constitute a family of boric acid and borate exporters, with seven members identified in A. thaliana (AtBOR1-7) $[18,19]$. AtBOR1 accumulates in the root stele under low-B conditions, and is responsible for xylem loading of $\left[\mathrm{B}(\mathrm{OH})_{3}\right]$, allowing $\mathrm{B}$ distribution to the rest of the plant $[7,18]$. It has been proven that the coordinated action of AtNIPs and AtBORs is essential to ensure a proper B distribution within the plant, especially under low-B conditions, what is required for a proper plant growth and development [20].

Various crops of agronomical interest belong to the legume family (Leguminosae or Fabaceae), such as alfalfa, pea, or soybean $[17,21]$. These plant species have the ability to interact symbiotically with $\mathrm{N}_{2}$-fixing Rhizobia, triggering the formation of root nodules, where biological nitrogen fixation takes place [22-24]. In this sense, developing more efficient nitrogen-fixing associations is of high importance given the pollution problems associated with the excessive use of chemical fertilizers $[25,26]$. This requires a better understanding of the factors that influence the success of the symbiotic process, including nutrient transport [27-29]. In line with this, it has been shown that every step in the establishment of Legume-rhizobia symbioses is severely affected by B deficiency [30-35]. However, B transport has been barely studied in legumes and the MIP protein superfamily seems to harbor putative B transporter candidates. In the model legume Medicago truncatula Gaertn, this superfamily comprises 46 MIPs, 18 of them belonging to the NIP family [36]. However, only one B transporter (a NIP protein) has been characterized so far [37], and none have been associated with $\mathrm{B}$ transport under B deficient conditions.

In the present study we use a candidate gene approach combined with a phenotypic analysis and a heterologous complementation assay to characterize MtNIP5;1 as a novel B transporter of $M$. truncatula, homologous to AtNIP5;1, that functions under low boron conditions. The results presented here will allow gaining further knowledge regarding B nutrition in leguminous plants.

\section{Results}

Boron stress causes developmental and growth defects in M. truncatula

In order to study $M$. truncatula response to B availability, a growth assay was carried out applying a B gradient. The plant phenotype and nitrogenase activity (for those plants growing under symbiotic conditions) were analyzed.

Plants growing under B deficiency showed chlorosis and the inhibition of leaf expansion and root growth. Generally, these symptoms were more evident in nodulated plants than in those fertilized with $\mathrm{N}$ (Fig. 1). Fewer and smaller nodules appeared in these plants compared to those growing under control conditions (Fig. 1). On the other hand, plants growing under B toxicity showed a comparable growth inhibition under symbiotic and non-symbiotic conditions. Generally, nodules of plants growing under B toxicity presented similar sizes to control nodules although a significant number of nodules appeared with smaller size. Biomass data supported most of these observations (Fig. 1a-c). Biomass reduction (of approximately 60\%) was observed in roots of both $\mathrm{N}$-fertilized and nodulated plants growing under $\mathrm{B}$ deficiency (Fig. 1b). A reduced nodule biomass was also found under B deficiency (Fig. 1c). Under B toxicity, plants showed a decrease in shoot and root biomass under symbiotic and non-symbiotic conditions (Fig. 1b). Nonetheless, nodules did not show an altered biomass under high B levels (Fig. 1c).

Nitrogenase activity was determined and expressed per plant (Fig. 1d) or relative to nodule number or nodule weight (Additional file 2), giving all similar results. Nodules of both B-deficiency and B-toxicity growing plants showed a significant reduction of nitrogenase activity. These results were consistent with the nodule defects observed under B deficiency (Fig. 1a). Interestingly, even though no significant differences were observed under B toxicity in nodule biomass, $\mathrm{N}$ fixation was severely affected under these conditions.

\section{Identification of AtNIP5;1 homologs in M. truncatula}

The A. thaliana NIP5;1, encoding an aquaporin that belongs to the MIP superfamily, was the first aquaporin discovered involved in boron transport in plants [15]. Sequence comparison of the encoded protein AtNIP5;1 (AT2G47160), showed that Medtr1g097840 (named MtNIP5;1) is the closest homolog to the A. thaliana B transporter in $M$. truncatula, showing $73.7 \%$ sequence identity (Fig. 2a).

Aiming to further characterize the MtNIP5;1 protein, a $3 \mathrm{D}$ protein structure prediction was performed as described in the Methods section. The predicted tertiary structure indicated that the encoded protein would be transmembranous, presenting six membrane-spanning helices, connected through loops, and two short helices connected via conserved NPS/NPV motifs, together forming the seventh transmembrane helix (Fig. 2b). The distribution of these seven helices would constitute a pore, a characteristic feature of aquaporin proteins [38]. Besides, the protein charge layout indicated the location 

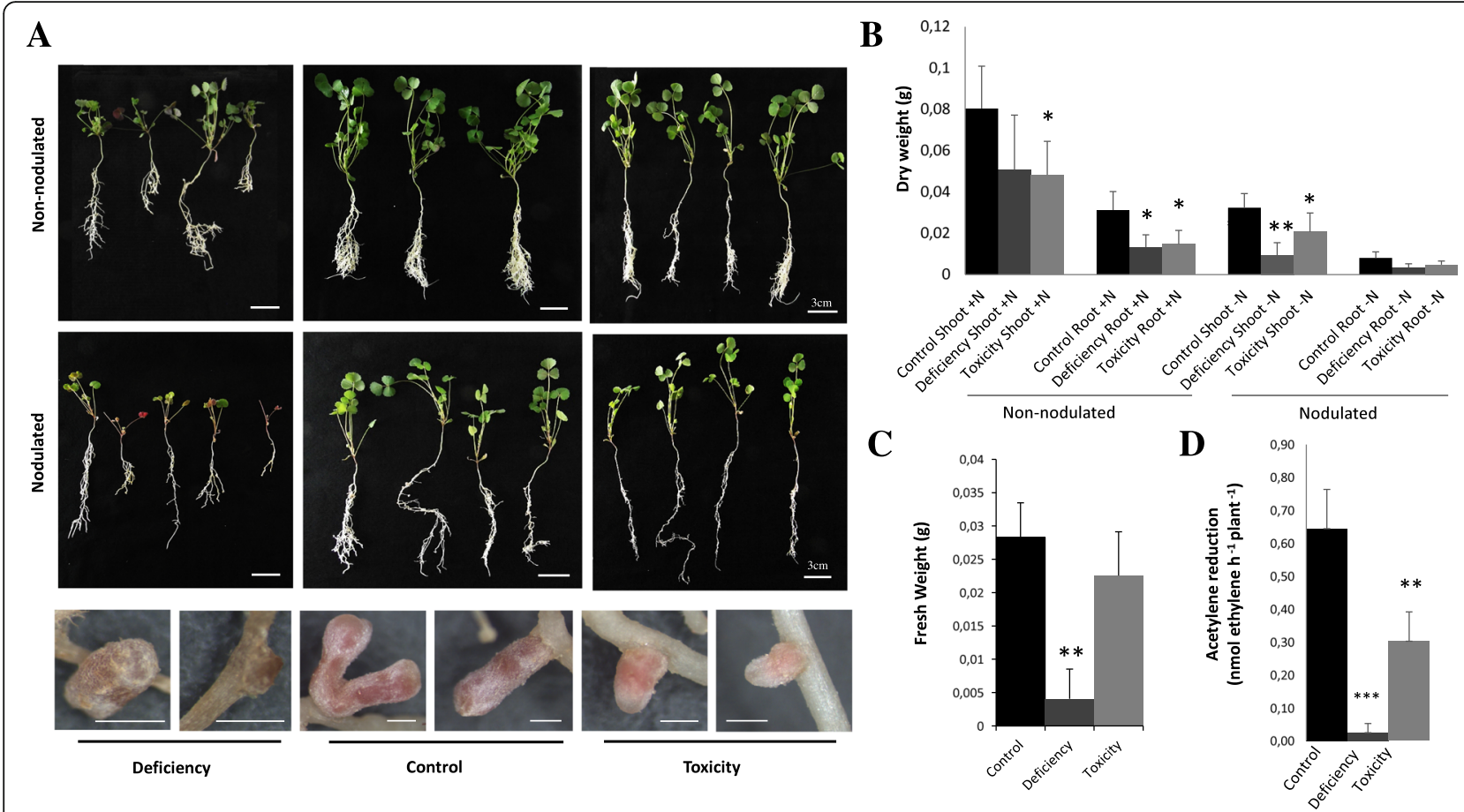

Fig. 1 Boron stress has an inhibitory effect on M. truncatula growth and nitrogenase activity. a Pictures of 4-week-old M. truncatula plants growing under a B gradient are shown. Upper panels (upper row of images) show plants fertilized with $\mathrm{N}$ (non-nodulated plants) growing under B deficiency (no B was supplemented into the media), control (media at a final B concentration of $0.1 \mathrm{mM} \mathrm{B}\left[\mathrm{OH}_{3}\right]$ ) or B toxic conditions (1 mM B $\left[\mathrm{OH}_{3}\right]$ ). Middle row of images shows plants growing under symbiotic conditions ( $M$. truncatula plants inoculated with S. meliloti 2011). Lower row of images shows nodules from plants grown under different B conditions, as indicated in the bottom labels. Bar $=3 \mathrm{~cm}$ (plant pictures) or $1 \mathrm{~mm}$ (nodule pictures). b Plant biomass as dry weight of roots and shoots of non-nodulated or nodulated plants under a B gradient. c Nodule fresh weight under a B gradient. Data are the Mean \pm SD of two independent experiments with, at least, four biological replicates ( $n=4)$. $\mathbf{d}$ Nitrogenase activity was determined in 4-week-old plants growing under a B gradient. Plants growing under control, B deficiency, or B toxic conditions were used to evaluate nitrogenase activity changes under different B conditions. Nitrogenase activity was analyzed by the acetylene reduction method ( $n$ mol ethylene generated per hour per plant). Data were analyzed using One-way analysis of variance (ANOVA) followed by tstudent post-hoc test. Asterisks indicate significant differences when comparing B stress samples with B control treatment ( $t$-Student, ("**" $=p<$ $0.05, " * * *=p<0.01, "$ "***" $=p<0.001)$

of positively charged residues in the external part of the pore, leaving the negative charges in the inside (Fig. 2b). On the other hand, a comparison between the amino acid sequences of MtNIP5;1 and its closest homolog in A. thaliana, AtNIP5;1, revealed that they share the dual NPAs motifs (being NPS/NPV) and the Ar/R selectivity filter (A-I-G-R) sequences as well as four of the five amino acids (P2-P5) that belong to the P1-P5 Froger's positions (being Y/F-T-A-Y-L, for AtNIP5;1 and MtNIP5;1, respectively) (Fig. 2c). This supports a shared role between these two proteins transporting boric acid across the plasma membrane $[36,39,40]$..

\section{MtNIP5; 1 expression is induced under B deficiency}

A qPCR assay was performed in three different tissues (roots, nodules, and aerial parts of nodulated and nonnodulated plants) in order to evaluate possible changes in the expression patterns of MtNIP5;1 under a B gradient. MtNIP5;1 expression was induced under B deficiency in both shoots and roots, although this induction was more pronounced in the latter. Besides, the expression was repressed in roots under B toxicity compared to control conditions. Nodules presented lower transcript levels compared to shoots and roots, and the induction did not change significantly among the three $B$ conditions tested (Fig. 3a). In silico analysis based on the Symbimics database [41] or the Medicago truncatula Gene Expression Atlas ( [42], ID Mtr.34598.1.S1_at) supports these results, showing much higher expression in roots compared to other plant organs (including nodules or the shoot/aerial part) (Additional file 3).

Going further, the tissue expression of this gene was evaluated by fusing the $\beta$-glucuronidase gene $(g u s)$ to the MtNIP5;1 promoter. $M$. truncatula seedlings were transformed with a construct containing the $2 \mathrm{~kb}$ region upstream of MtNIP5;1 fused to gus. The blue GUS staining was detected in roots and nodules of control and Bdeficient plants 4 weeks postinoculation (Fig. 3b). As indicated by qPCR, MtNIP5;1 was highly expressed in roots, especially under B deficiency. More specifically, 


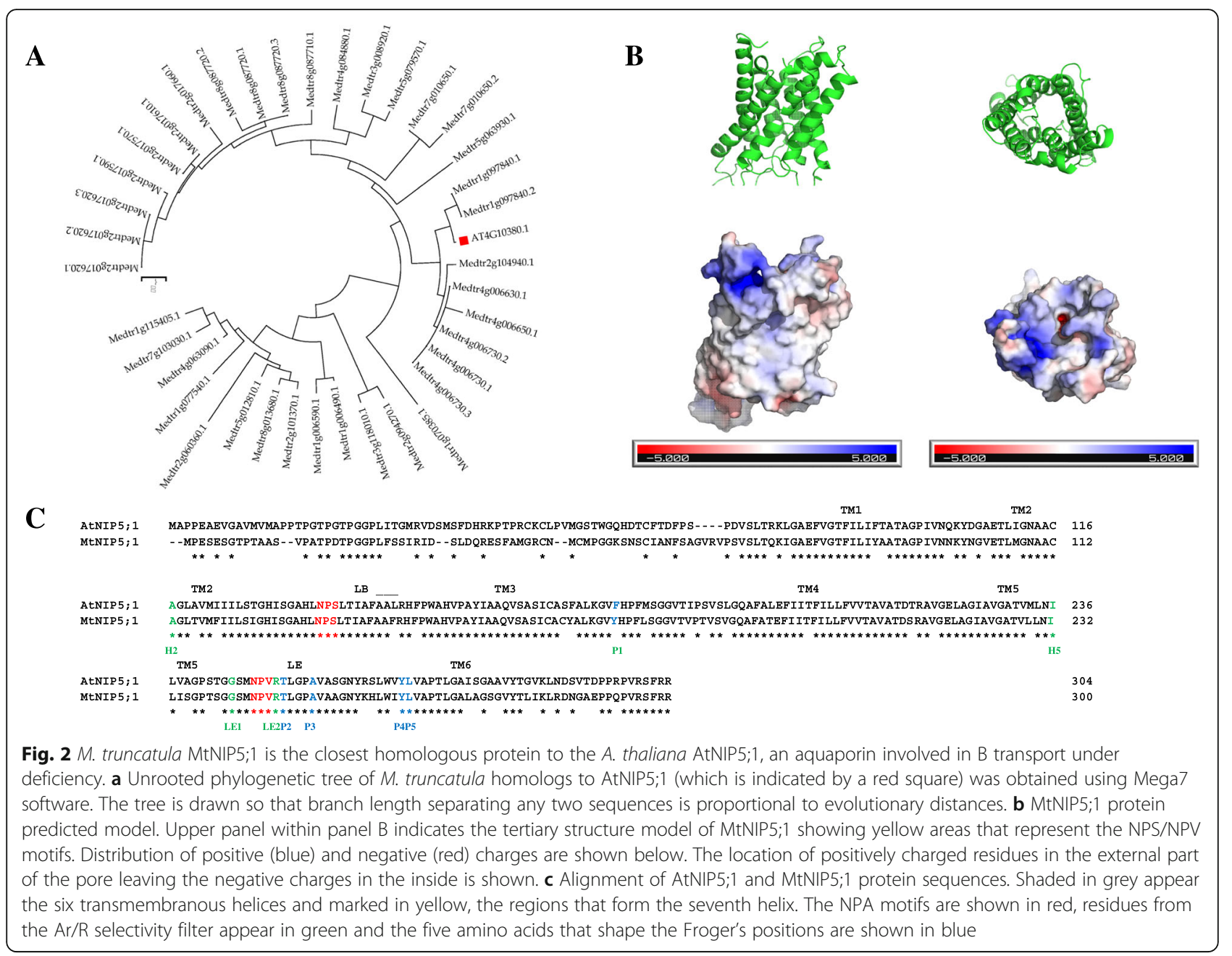

the activity was located at the root vasculature. Nodules also presented GUS activity located in the vasculature zone, with a more intense signal under B deficiency (Fig. $3 b)$.

\section{MtNIP5; 1 localizes at the plasma membrane in the epidermis of roots and in the epidermal and cortical cells of nodules}

Transient transformation of Nicotiana benthamiana Domin leaves was performed aiming to analyze the subcellular location of MtNIP5;1. Agrobacterium tumefaciens containing either $p 35 S::$ MtNIP5;1-green fluorescent protein (GFP) or p35S::AtPIP2A-cyan fluorescent protein $(C F P)$ constructs were co-infiltrated as described in the Methods section. An overlapping signal was observed between MtNIP5;1 fused to the GFP fluorophore and the plasma membrane marker, indicating that MtNIP5;1 is located at the plasma membrane (Fig. 4). Controls in which no fluorophores were used, showed no signal in the measured channels (Fig. 4).
The chimeric MtNIP5;1-HA protein was used in the immunohistochemical studies. $M$. truncatula plants were transformed with the genomic region of MtNIP5;1 fused in-frame with three haemagglutinin (HA) epitopes in the C-terminus (MtNIP5;1-HA), using the same promoter region as the one used for GUS activity analysis. MtNIP5;1-HA was detected (DsRed channel) with a mouse anti-HA antibody and an Alexa594-conjugated anti-mouse secondary antibody. Images showed protein localization at the epidermal cells of roots (including root hairs) (Fig. 5a) under both B conditions (although being slightly higher under deficiency). Besides, in nodules, the signal decreased compared to root epidermis and appeared in some infected and non-infected nodule cells, nodule cortex, and surrounding the vasculature (Fig. 5b). Intriguingly, MtNIP5;1-HA signal distribution was not consistent with the tissue-specific expression observed in the GUS staining assays, where an intense signal appeared located exclusively at the vasculature of roots and nodules (Fig. 3). Controls in which no Alexa 594-conjugated antibody was used showed no signal in the measured channels (Fig. 5). 


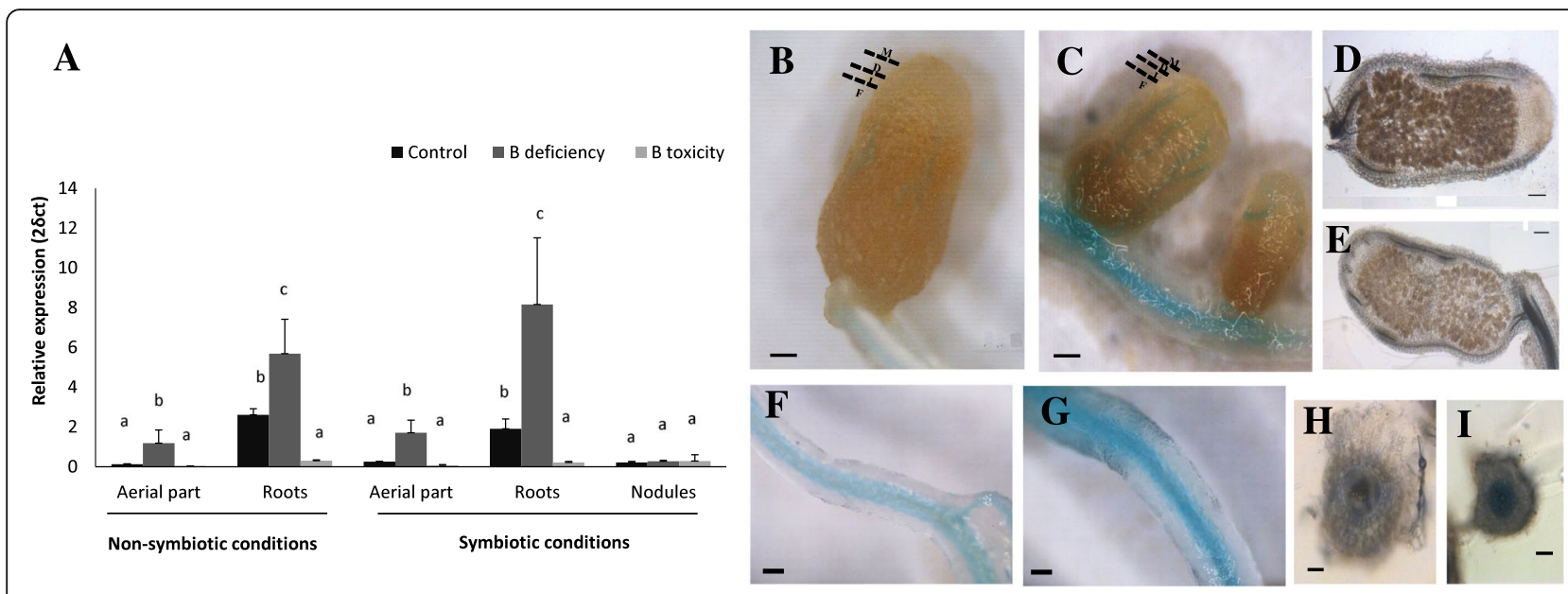

Fig. 3 MtNIP5;1 expression is induced under B deficiency. a mRNA accumulation was quantified by qPCR in roots, shoots, and nodules of plants fertilized with $\mathrm{N}$ or growing under symbiotic conditions. Plants grew under a $\mathrm{B}$ gradient consisting of the following treatments: control conditions $\left(0.1 \mathrm{mM} \mathrm{B}\left[\mathrm{OH}_{3}\right]\right)$, deficiency $\left(0 \mathrm{mM} \mathrm{B}\left[\mathrm{OH}_{3}\right]\right)$, or B toxicity $\left(1 \mathrm{mM} \mathrm{B}\left[\mathrm{OH}_{3}\right]\right)$. Data are the Mean $\pm \mathrm{SD}$ of two independent experiments with, at least, four pooled plants and four biological replicates $(n=4)$. Different letters indicate significant differences (One-way ANOVA followed by Tukey test, $p<0.05$ ). MtNIP5; 1 expression is presented as expression relative values to the internal gene Ubiquitin carboxyl-terminal hydrolase 1 . b-i Tissue expression localization of PMTNIP5; 1:GUS appears at the vasculature and is induced under B deficiency. Blue GUS staining analysis in pMtNIP5; 1::GUS appears in the vasculature of (b-e): nodules and (f-i): roots. $\mathbf{b}, \mathbf{d}, \mathbf{f}$, and $\mathbf{h}$ show B control treatment $\left(0.1 \mathrm{mM} \mathrm{B}^{\mathrm{O}}\left[\mathrm{OH}_{3}\right]\right),(\mathbf{c}, \mathbf{e}, \mathbf{g}$, and i): B deficiency treatment. M: meristematic zone, D: differentiation zone, l: interzone $\mathrm{F}: \mathrm{N}_{2}$ fixation zone. $\mathrm{Bar}=0.5 \mathrm{~cm}$

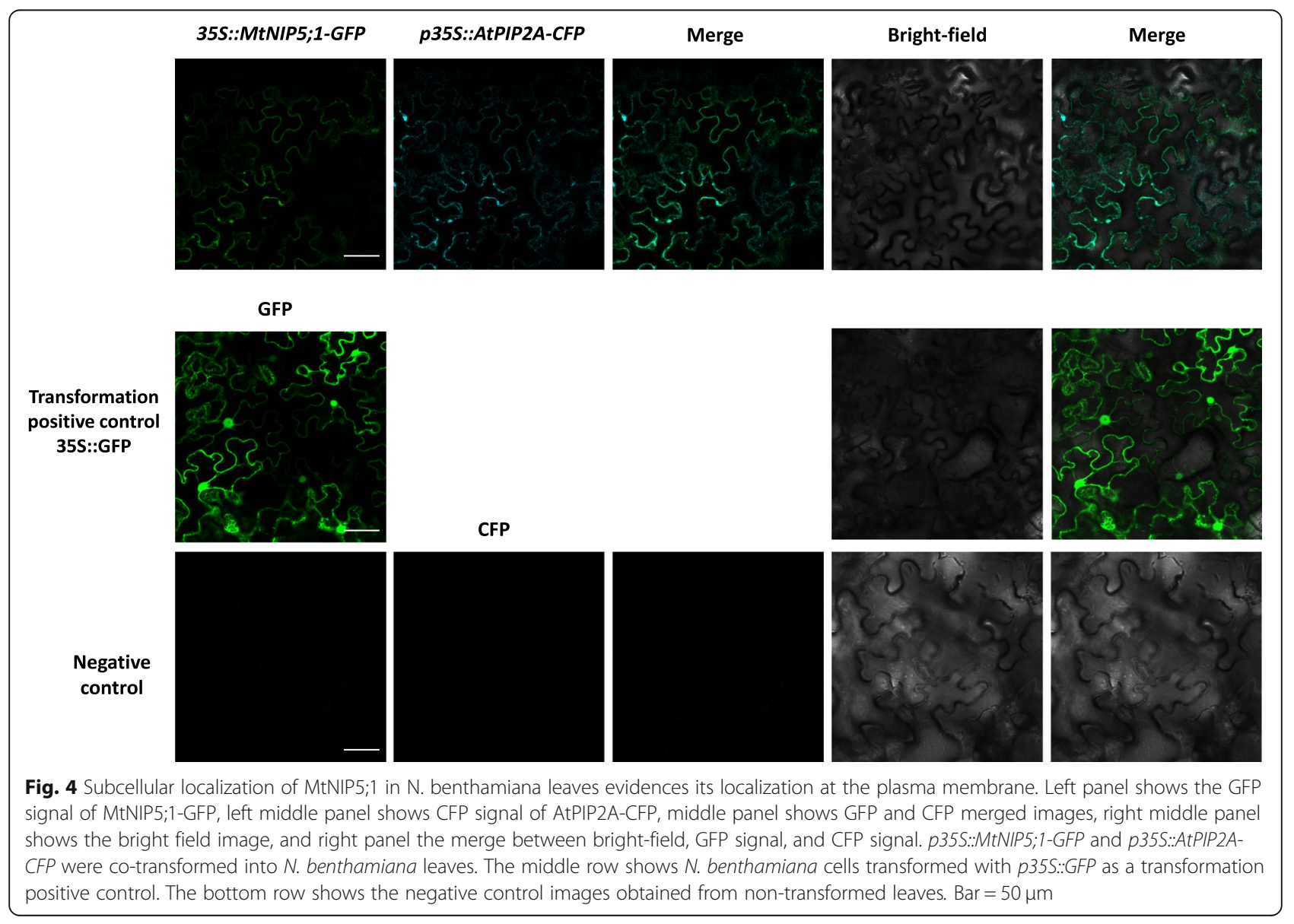




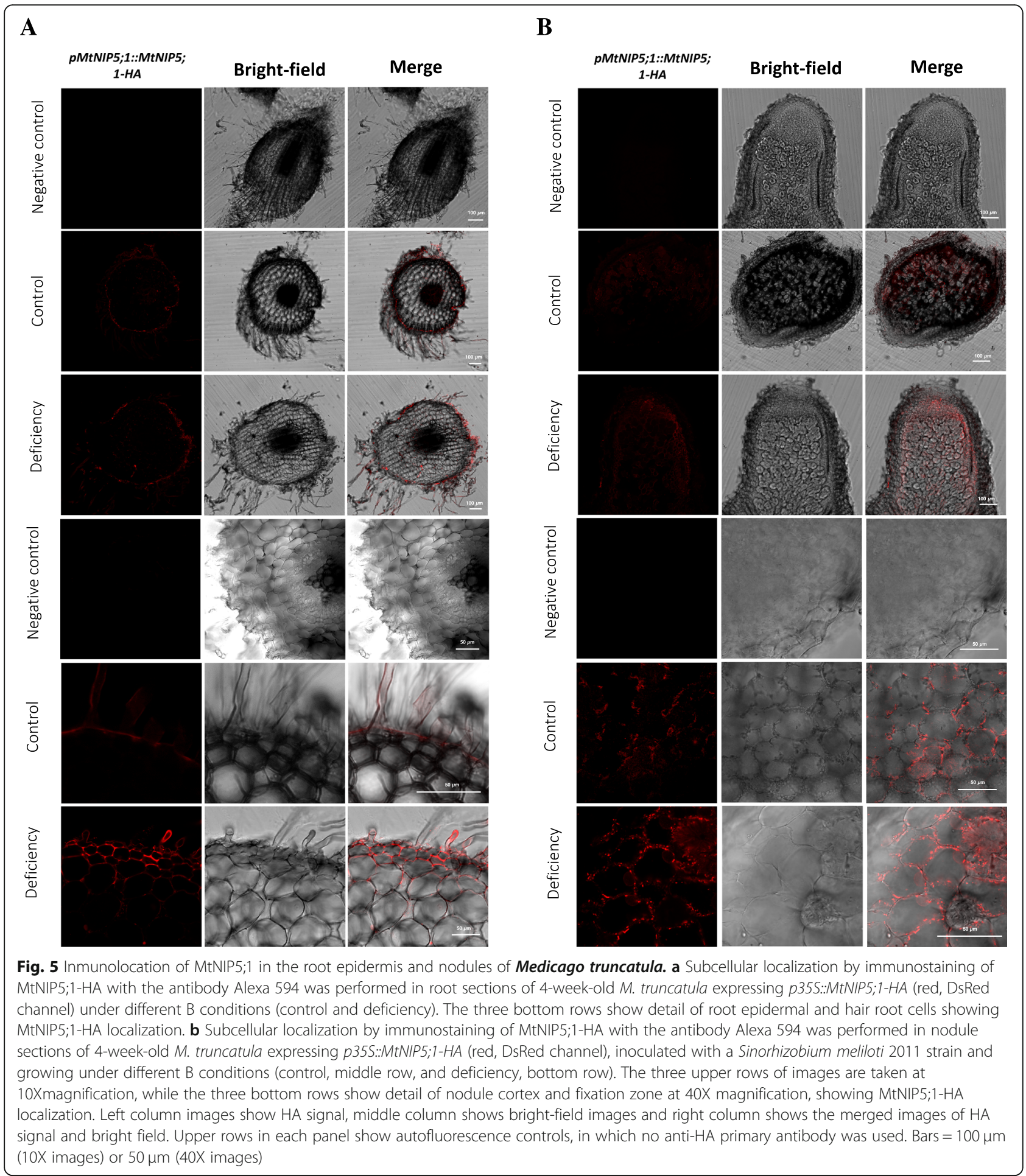

\section{Partial complementation of nip5;1 A. thaliana mutant} supports a role of MtNIP5; 1 as a B transporter

Aiming to characterize functionally this putative $\mathrm{B}$ transporter, a heterologous expression system in A. thaliana was used. Thus, the A. thaliana nip5;1-1 mutant [15] was transformed with the p35S::MtNIP5;1-GFP construct, and two independent homozygous single-copy lines were obtained (p35S:: MtNIP5;1-GFP 1 and p35S:: MtNIP5;1-GFP 2). These lines were used to test MtNIP5;1 capability to uptake B and thus complement the mutant phenotype. WT, nip5;1-1 and nip5;1-1 mutant lines overexpressing MtNIP5;1 were grown under 
two B conditions, control $\left(100 \mu \mathrm{M} \mathrm{B}[\mathrm{OH}]_{3}\right)$ and deficiency $\left(0.03 \mu \mathrm{M} \mathrm{B}[\mathrm{OH}]_{3}\right)$.

A phenotypical analysis was performed in order to evaluate the effects of reduced $B$ availability in root growth over time (Additional file 4). These effects on primary root length were already noticeable at 3 days postgermination, when nip5;1-1 roots started to show a significantly lower length compared to the $\mathrm{Wt}$ and to the two mutant lines overexpressing MtNIP5;1. In fact, at the end of the experiment (10 days after germination), both mutant lines overexpressing MtNIP5;1 tripled the length of the mutant primary root growing under B deficient conditions confirming a partial complementation of the mutation by overexpression of MtNIP5;1 (Fig. 6 a and $b$ ).

Furthermore, in order to evaluate the ability of MtNIP5;1 uptaking B and to determine if the growth rescue observed in the overexpressing lines was correlated with an increase of $\mathrm{B}$, the micronutrient concentration was quantified in 10-days old seedlings growing under control and B deficient conditions. As shown in Fig. 6c, both $A$. thaliana MtNIP5;1 expressing lines (p35S::MtNIP5;1-GFP 1 and p35S::MtNIP5;1-GFP 2) showed a significant increase in B concentration recovering B concentration to Wt levels. On the contrary, calcium (Ca) concentration did not show differences among lines under B deficiency, although it appeared reduced in both overexpressing lines under control conditions (Additional file 5).

\section{Discussion}

Under the context of food security, sustainable agriculture, and climate change, the interest of understating $B$ transport and B stress tolerance in legumes, particularly under symbiotic conditions, has been increasingly higher, aiming to minimize the impact of this nutrient stress on yields $[43,44]$. Thus, this work, by using the model legume plant $M$. truncatula, aimed to further understand $\mathrm{B}$ transport in legumes, considering that no B transporter involved in B transport under deficient conditions has been characterized till date in this agronomically important plant family.

Together with the energy-dependent high-affinity B transport system constituted by the BOR family, different members of the MIP family possess a role transporting (and therefore, distributing) $\mathrm{B}$ in plants $[15,45]$. The

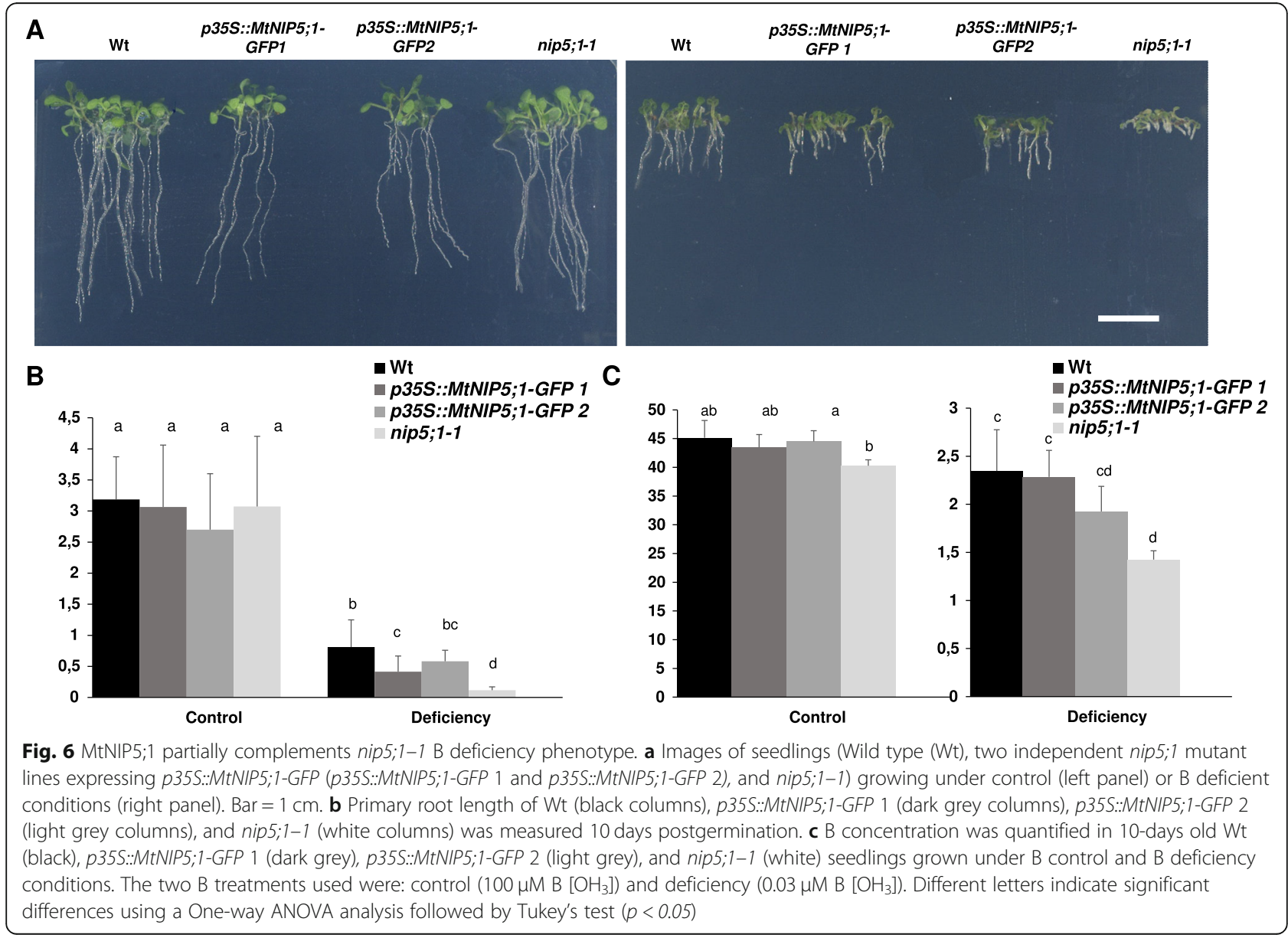


A. thaliana NIP5;1 was the first described aquaporin implicated in the uptake of $\mathrm{B}$ from the soil into the roots. AtNIP5; 1 acts coordinately with AtBOR1 (identified and characterized a few years earlier) to ensure the uptake and correct distribution of $\mathrm{B}$ under deficient conditions $[15,20]$. From there, the use of homology-based analysis has allowed the identification of many B transporters in different plant species (including rice, barley, or M. truncatula). However, most of these are functionally related to an increased tolerance to high B (i.e. MtNIP3, [22]).

Many different MIP family members, including those that belong to the Tonoplast membrane Intrinsic Proteins (TIP) subfamily (such as AtTIP5;1 [46]) or to the Plasma membrane Intrinsic Proteins (PIP) subfamily (such as the barley Hv-PIP1;3 and Hv-PIP1 [12], the maize ZmPIP1 [47] or the rice OsPIP2;4, OsPIP2;7, OsPIP1;3 and OsPIP2;6 members [48]), have been found to be involved in the transport of B in plants. MtNIP3 was identified as a homologous protein to AtNIP6;1 (sharing $75 \%$ of amino acid sequence similarity) in $M$. truncatula, a close relative to the forage legume alfalfa and widely used as a model plant for genetic and genomic studies [49]. MtNIP3 physiological role was related to conferring a high $B$ tolerance, as it showed higher leaf expression levels in B tolerant cultivars, which correlated positively with lower B concentrations in leaves [22].

In the present study, we search for homologs to AtNIP5;1 in M. truncatula aiming to identify putative B transporters involved in B transport under B deficiency. The analysis yielded MtNIP5;1 protein as the most promising candidate that may function as AtNIP5;1 based on the amino acid sequence similarity (sharing $73.7 \%$ amino acid identity, Fig. 2a). This protein was previously pointed as a putative $B$ transporter homolog to AtNIP5;1 by Bogacki et al. [22] although no further analyses were carried out to prove its functional role, as this work focused on studying the role of another $M$. truncatula NIP protein, MtNIP3 (Medtr4g006730.1), that functions as a B transporter under B toxicity. This previous work together with the results here presented, support distinct roles of NIP proteins in B transport, being involved in toxicity and deficiency responses $[14,15]$. Our results showed that B deficiency induces MtNIP5;1 expression mainly in roots, but also in shoots (Fig. 3a). Furthermore, B toxicity can repress this gene expression specifically in roots, which supports a possible role of this $M$. truncatula NIP protein uptaking B. Besides, this result raises interesting questions regarding AtNIP5;1 expression regulation by $\mathrm{B}$ conditions. Noteworthy, as found in AtNIP5;1, the $5^{\prime}$ untranslated region (5'UTR) of MtNIP5;1 (Additional file 6), may play pivotal roles in controlling the transcript accumulation in response to $\mathrm{B}$ conditions [50].
Going further in the analysis, MtNIP5;1 3D structure was predicted. From this analysis, it was inferred that MtNIP5;1 is a transmembrane protein according to its predicted structure, like AtNIP5;1. It presents the characteristic structure conserved among aquaporins (with seven helices with neutral charge distribution) ( [51], Fig. 2b). AtNIP5;1 had been previously described as a transmembrane protein located in the plasma membrane [17]. Besides, the presence of NPA dual motifs (NPS/ NPV in this case) in MtNIP5;1 is also a conserved feature among aquaporins, whose function is to facilitate the exit of protons when solutes pass through the channel [52]. Furthermore, aquaporins' selectivity filter seems to be determined by the amino acids present in the NPA dual motifs, the Ar/R selectivity filter composition, and also the five Froger's positions (P1-P5) [40, 53]. In the case of the five amino acids located at the Froger's positions, they may not only be involved in the discrimination between water and glycerol (distinguishing aquaporins from aquaglyceroporins), but also P2-P5 amino acids (and not P1, that is shown not conserved among MIPs for the same substrate) could be relevant discriminating other substrates due to their potential interaction with them [40]. Thus, the high similarity found in these amino acid sequences in MtNIP5;1 and AtNIP5;1 (Fig. 2c) provides further evidence in support of a comparable permeability of non-aqua substrates, such as boric acid [36, 40].

In $A$. thaliana, AtNIP5;1 localizes at the plasma membrane of root epidermal cells functioning as a boric acid channel responsible for B uptake under B limited conditions $[15,17]$. In here, protein localization showed similar patterns. MtNIP5;1 appeared localized at the plasma membrane (Fig. 4) and at the root epidermal cells (Fig. 5 ), what fits well with a role of this facilitator protein ensuring B incorporation. However, an intriguing result was obtained when comparing GUS expression patterns and protein localization analysis as they show differential expression and localization patterns (Figs. 3 and 5). Further analysis should be carried out to investigate these results that resemble those of AtNIP1;1, an AtNIP5;1 homolog protein, what may indicate a cell type-specific posttranscriptional regulation of these aquaporins, including MtNIP5;1 [54].

Interestingly, expressing MtNIP5;1 under the control of the cauliflower mosaic virus 35S RNA (CaMV 35S) promoter complemented partially root growth defects shown by nip5;1-1 under B deficiency $(0.03 \mu \mathrm{M}$ B [OH3]) (Fig. 6), and this partial phenotype rescue was well correlated with a higher B content in the overexpressing lines (Fig. 6c). These results suggest, on one hand, that MtNIP5;1-GFP is functional in planta and on the other, that MtNIP5;1 shares functional similarity with AtNIP5;1. Therefore MtNIP5;1 is the first 
characterized B transporter acting under B deficiency in legumes. In this regard, several reports have shown the symbiosis reliance on B [31, 33-35, 55]. In here, when plants were subjected to deficiency, a characteristic B stress response was observed in nodulated plants, consisting in a lower nodule number, which were smaller in size and brownish and with a reduced nitrogenase activity (Fig. 1). This supports a role of B in nitrogen fixation (Fig. 1d) [30, 34, 35]. In fact, it was initially hypothesized that MtNIP5;1 could play a distinctive role in transporting $\mathrm{B}$ to nodules under deficiency. However, and despite observing that MtNIP5;1 localizes to this organ (Fig. 5b), the lack of induced expression under deficiency (Fig. 3a) does not support a unique role of this transporter in B uptake under deficiency in nodules. Nonetheless, it still cannot be ruled out a helper role of this aquaporin in uptaking B under B limiting conditions in nodules.

\section{Conclusions}

Overall, the studies here performed aimed at characterizing putative $\mathrm{B}$ transporters of $M$. truncatula belonging to the aquaporin NIP subfamily, functioning under B deficiency. A homology-based analysis pointed to MtNIP5; 1 as the most promising candidate to function as AtNIP5;1 in this legume model plant. The induced expression under B deficiency and the repression under B toxic levels, together with this protein localization patterns and the partial complementation of nip5;1 mutant, support a role of MtNIP5;1 functioning as a B transporter under $B$ deficiency. These results might help better understanding $\mathrm{B}$ transport in legumes, what could help developing tolerant cultivars better adapted to B deficient soils. In line with this, it would be interesting to investigate further if legume tolerant varieties present higher expression of this MtNIP5;1 (or homologous candidates), as has been done with other aquaporins in $M$. truncatula or barley, in which it was linked the tolerance to $B$ toxicity with gene function.

\section{Methods}

\section{Plant growth conditions}

Seeds of M. truncatula ecotype R108, obtained from the Noble Research Institute, were scarified with sulfuric acid $\left(\mathrm{H}_{2} \mathrm{SO}_{4}\right)$, sterilized with bleach before they were germinated in $0.8 \%$ agar plates, and placed in the dark at $4{ }^{\circ} \mathrm{C}$ for $48 \mathrm{~h}$, following the steps described by TejadaJiménez et al. [56]. After stratification, plates were moved to a growth chamber at $22^{\circ} \mathrm{C}$ for $24 \mathrm{~h}$ with a 16 $\mathrm{h}: 8 \mathrm{~h}$ light:dark cycle. Seedlings used for phenotypic or RT-qPCR analyses were transferred to pots using perlite as a substrate and grown in the greenhouse with a longday photoperiod $\left(16 \mathrm{~h}: 8 \mathrm{~h}\right.$ light:dark cycle at $\left.18-25^{\circ} \mathrm{C}\right)$. Greenhouse plants were irrigated every 2 days with Jenner's solution or water, alternatively [57]. Jenner's solution was supplemented or not with B (to achieve control or B deficient conditions, respectively) and $\mathrm{N}$ (to achieve non-symbiotic or symbiotic conditions).

$N$. benthamiana plants, obtained from Dr. GonzálezGuerrero's Laboratory (CBGP-UPM/INIA, Spain), were pre-germinated in peat for $10-15$ days at $20-22^{\circ} \mathrm{C}$ with a $16 \mathrm{~h}: 8 \mathrm{~h}$ photoperiod. They were then transplanted to peat:vermiculite 3:1 and grown for 3-4 weeks in a greenhouse at $18-25^{\circ} \mathrm{C}$ and long-day photoperiod.

A. thaliana ecotype Col-0 and nip5;1-1 mutant seeds [58], obtained from Dr. Miwa Laboratory (Hokkaido University, Japan), were sterilized first in ethanol $70 \%$ and then in bleach $50 \%$ with a droplet of Tween-20. After rinsing well the seeds with $\mathrm{H}_{2} \mathrm{O}_{\mathrm{d}}$, they were kept overnight in the dark at $4{ }^{\circ} \mathrm{C}$ and then germinated in plates with half-strength MS medium [59]. For segregation experiments, seedlings were transplanted to peat: perlite $3: 1$ and grown in a growth chamber at $23{ }^{\circ} \mathrm{C}$ with long-day photoperiod.

\section{Phenotypic analysis}

In order to study B-availability effects on plant growth, inoculated and non-inoculated $M$. truncatula plants were irrigated with different concentrations of $\mathrm{B}[\mathrm{OH}]_{3}$. Control treated plants were irrigated with $0.1 \mathrm{mM} \mathrm{B}$ $[\mathrm{OH}]_{3}$, toxicity conditions were achieved by irrigating plants with a final $\mathrm{B}[\mathrm{OH}]_{3}$ concentration of $1 \mathrm{mM}$, and no $\mathrm{B}[\mathrm{OH}]_{3}$ was applied for deficiency conditions. All irrigation media was treated with Amberlite ${ }^{\circ}$ IRA743 to eliminate B traces.

Plants grown under symbiotic conditions were inoculated with Sinorhizobium meliloti FSM-MA strain [60] without receiving any external input of $\mathrm{N}(-\mathrm{N})$. Noninoculated plants were supplemented with $20 \mathrm{mM}$ $\mathrm{NH}_{4} \mathrm{NO}_{3}(+\mathrm{N})$.

Plant tissue was collected 5 weeks after the transplant (4 weeks after inoculation) for biomass measurements, nitrogenase activity, and RT-qPCR assays.

Biomass as fresh weight was determined immediately after plant harvesting. Biomass as dry weight was determined after drying the plant tissue at $60^{\circ} \mathrm{C}$ for $72 \mathrm{~h}$.

Nitrogenase activity was measured using the acetylene reduction assay as described by Hardy et al. [61]. Briefly, roots of nodulated plants were placed in $30 \mathrm{ml}$ vials where $3 \mathrm{ml}$ of air were replaced with $3 \mathrm{ml}$ of acetylene. After $30 \mathrm{~min}, 4$ replicates of $0.5 \mathrm{ml}$ each were extracted and their ethylene content was measured using a gas chromatograph Shimadzu GC-2014 (Japan). A dilution of ethylene and acetylene $0.413 \mathrm{mg} / \mathrm{l}$ was used as standard. At the end, nodules were counted and weighed.

\section{Gene candidate identification}

To identify AtNIP5;1 homologous genes that putatively encode B facilitator transporters in M. truncatula, the 
AtNIP5;1 (At4g10380) sequence was obtained from the TAIR database [62] and BLAST in the M. truncatula genome using the Phytozome database [63].

\section{Gene expression analysis by RT-qPCR}

Gene expression studies were carried out by real-time RT-PCR (Applied Biosystems ${ }^{\circ}$ ) in order to analyze transcript levels of candidate genes. RNA extraction was carried out using the RNeasy Mini Kit (Qiagen). cDNA was obtained from $500 \mathrm{ng}$ of DNA-free RNA using PrimeScript $^{\text {mi }}$ (Takara Bio Inc., Japan). Primers used are indicated in Additional file 1. RNA levels were normalized by using the ubiquitin carboxy-terminal hydrolase gene as an internal standard for $M$. truncatula expression patterns [64].

\section{M. truncatula transformation}

The Agrobacterium rhizogenes ARqua1 strain containing the vector was used to transform $M$. truncatula seedlings $18 \mathrm{~h}$ after germination in a growth chamber at $22{ }^{\circ} \mathrm{C}$. Transformation experiments were performed following the protocols described by Boisson-Dernier et al. [65]. Transformed seedlings were later transferred to Farhaeus media plates supplemented with kanamycin $(50 \mu \mathrm{g} / \mathrm{ml})$ as a selection marker [66]. After 3 weeks, plants were transplanted to sterile perlite pots that were placed in the greenhouse at $18-25^{\circ} \mathrm{C}$ and long-day photoperiod.

\section{GUS staining}

The MtNIP5;1 promoter:: $\beta$-glucuronidase (GUS) construct was generated using the Gateway System (Life Technologies, Carlsbad, USA). The promoter fragment of the candidate gene (2022 kb upstream of the MtNIP5; 1 start codon, $\mathrm{P}_{-1174}$ UT848) was amplified using the primers indicated in Additional file 1, cloned in the pDONOR27 vector (Invitrogen), and transferred to the pGWB3 plasmid [67].

Gus activity assay was performed in plants 4 weeks after inoculation following the protocol described by Vernoud et al. [68] with minor modifications. Roots and nodules sections $(100 \mu \mathrm{m})$ were incubated in a GUS buffer $\left(0.69 \% \mathrm{PO}_{4} \mathrm{H}_{2} \mathrm{Na}, 0.5 \mathrm{M}\right.$ EDTA pH 8, 30\% sarkosyl, $40 \mu \mathrm{l}$ triton $\mathrm{X}-100$, and $\mathrm{H}_{2} \mathrm{O}$ ) supplemented with X-Gluc $(0.1 \mathrm{mg} / \mathrm{ml})$ for $12-16 \mathrm{~h}$ at $28^{\circ} \mathrm{C}$ in the dark, and then distained with bleach $50 \%$ and rinsed five times in $\mathrm{H}_{2} \mathrm{O}$. Afterwards, sections were observed with a Leica DM IRB microscope.

\section{Immunohistochemistry and confocal microscopy}

MtNIP5;1 gene and its native promoter (2 kb upstream of the start codon) were amplified with the primers indicated in Additional file 1 and cloned into the plasmid pGWB13 that fuses three C-terminal hemagglutinin
(HA) tags in-frame using the Gateway system (Life Technologies, Carlsbad, USA).

Transformed plants were inoculated with S. meliloti 2011. Roots and nodules were fixed overnight in a $4 \%$ paraformaldehyde, $2.5 \%$ sucrose, and PBS buffer at $4{ }^{\circ} \mathrm{C}$. After several washes in PBS, the tissue was embedded in $6 \%$ agarose and $100 \mu \mathrm{m}$ sections were prepared in a Vibratome 1000 plus. Sections were dehydrated using methanol series $(30,50,70,100 \%$ in PBS) for $5 \mathrm{~min}$ and then rehydrated. The immunostaining was started permeabilizing plant cell walls with $4 \%$ cellulase in PBS for $1 \mathrm{~h}$ at RT and with $0.1 \%$ Tween 20 in PBS for $15 \mathrm{~min}$. Sections were blocked with $5 \%$ bovine serum albumin (BSA) in PBS before their incubation with anti-HA mouse monoclonal antibody (Sigma) for $2 \mathrm{~h}$ at room temperature. After several washes, sections were incubated for $1 \mathrm{~h}$ with Alexa594-conjugated anti-mouse rabbit monoclonal antibody (Sigma). Images were acquired using a confocal laser-scanning microscope (Leica SP8) at $561 \mathrm{~nm}$ for Alexa 594 imaging using identical settings in each magnification (10X or $40 \mathrm{X}$ ) in order to make qualitative comparisons among tissues (roots and nodules under control or deficient conditions).

\section{$N$. benthamiana transient expression assay}

The MtNIP5;1 gene was amplified using the primers indicated in Additional file 1, and then cloned into the pGWB5 plasmid, which fuses CaMV 35S promoter and the GFP tag C-terminally [67]. A. tumefaciens C58C1 [69] was transformed with either p35S::MtNIP5;1-GFP or the construct $p 35 S:: A t P I P 2 A-C F P$ [70] together with the silencing suppressor p19 of the Tomato bushy stunt virus [71]. N. benthamiana 3 weeks-old leaves were then infiltrated following the protocol described by Sparkes et al. [72]. Images were taken $48 \mathrm{~h}$ after agroinfiltration with a confocal microscope (Leica SP8).

\section{Bioinformatic analysis}

The aminoacidic sequence of the gene candidate was obtained from the database UniProt [73]. Protein 3D models were predicted using I-TASSER [74] and were edited with the software PyMol.

\section{A. thaliana mutant complementation assay}

A. tumefaciens strains containing the construct $p 35 S$ :: MtNIP5;1-GFP were used to transform the nip5;1-1 A. thaliana mutant [58] using the floral dipping transformation method as described by Zhang et al. [75]. Homozygous lines containing the construct of interest were selected by kanamycin selection and PCR analysis, using the primers included in Additional file 1.

Seeds of A. thaliana Col-0 (wildtype, Wt), the mutant nip5;1-1, and two homozygous independent lines incorporating the construct p35S::MtNIP5;1-GFP were 
grown vertically in plates of $1 / 2$ MS medium with two $B$ treatments: control $\left(100 \mu \mathrm{M} \mathrm{B}[\mathrm{OH}]_{3}\right)$ and deficiency $\left(0.03 \mu \mathrm{M} \mathrm{B}[\mathrm{OH}]_{3}\right)$. Primary root length was then measured at $3,5,7$, and 10 days post-germination, from the root tip to the hypocotyl boundary, using the online available software ImageJ [76].

B concentration was analyzed following Gómez-Soto et al. [77] methodology. Briefly, a pool of seedlings (4050 seedlings) were collected 10 days after germination and dried out at $65^{\circ} \mathrm{C}$. Dried samples (using three replications per line and treatment) were then submitted to the Elemental Analysis Unit at the Interdepartmental Investigation Service Laboratory at the Universidad Autónoma de Madrid (SIdI-UAM, Madrid, Spain). Plant dry matter underwent acid digestion in a microwave oven and was later analyzed using the ICP-MS NexION 300XX (Perkin Elmer Inc., Hopkinton, MA, USA), as described by Reguera et al. [78].

\section{Statistical analysis}

One-way analysis of variance (ANOVA) followed by a Tukey HSD post-hoc test was applied to perform multiple comparisons at a probability level of $5 \%(p<0.05)$. The SPSS Statistics 17.0 (SPSS Inc.) package was used for the statistical analyses.

\section{Supplementary Information}

The online version contains supplementary material available at https://doi. org/10.1186/s12870-020-02750-4.

\section{Additional file 1: Table S1 Primer list. \\ Additional file 2: Fig. S1. Nitrogenase activity was determined in 4- week-old plants growing under a B gradient: control conditions (media at a final $B$ concentration of $0,1 \mathrm{mM} \mathrm{B}[\mathrm{OH} 3]$ ), $B$ deficiency (no $B$ supple- mented into the media), or B toxic conditions (1 mM B[OH3]). Nitroge- nase activity was analyzed by the acetylene reduction method and expressed as nmol of ethylene generated per hour per nodule number (left panel) or per nodule weight (right panel). Data are the Mean \pm SD of two independent experiments with, at least, four pooled plants and four biological replicates $(n=4)$. Asterisks indicate significant differences when comparing B stress plants with B control treated plants (t-Student, "** = $p<0.01, "$ "**" $=p<0.001$ ).}

Additional file 3: Fig. S2. Expression of Medicago truncatula MtNIP5;1 (Medtr1g097840) in different plant organs. A) Data obtained from the Symbimics database (https://iant.toulouse.inra.fr/symbimics/). B) Data obtained from the Medicago Gene Expression Atlas (https://mtgea.noble. org/v3/).

Additional file 4: Fig. S3. Time cource experiment showing primary root growth of $A$. thaliana seedlings in nip5; 1-1 complementation assays. Primary root growth $(\mathrm{mm})$ of Wild type $(\mathrm{Wt})$ (black line), two independent lines expressing p35S::MtNIP5;1-GFP construct (p355::MtNIP5;1-GFP 1 and p35S::MtNIP5; 1-GFP 2, dark and light grey lines, respectively), and nip5; 1-1 (dashed line) were measured 3,5,7 and 10 days postgermination. Seedlings were grown under two B treatments: A) control $(100 \mu \mathrm{M} \mathrm{B}[\mathrm{OH}]$, and $\mathbf{B})$ deficiency $(0.03 \mu \mathrm{M} B[\mathrm{OH} 3]$

Additional file 5: Fig. S5. Calcium (Ca) concentration was quantified in 10-days old Wild Type (Wt) (black), p355::MtNIP5; 1-GFP 1 (dark grey), p35S::MtNIP5; 1-GFP 2 (light grey), and nip;1-1 (white) seedlings grown under $\mathrm{B}$ control and $\mathrm{B}$ deficiency conditions. The two $\mathrm{B}$ treatments used were: control $(100 \mu \mathrm{M} B[\mathrm{OH} 3]$ and deficiency $(0.03 \mu \mathrm{M} B[\mathrm{OH} 3$. Different letters indicate significant differences using a One-way ANOVA analysis followed by Turkey's test $(p<0.05)$.

Additional file 6: Fig. S6.A)Sequence alignment of the UTR regions of AtNIP5;1 (AT2G47160) and MtNIP5;1 (Medtr1g097840). B) End of the 5' untranslated region (5'UTR) of MtNIP5;1 (Medtr1g097840) and the initial sequence of the gene (starting from the ATG starting codon).

\section{Abbreviations}

B: Boron; N: Nitrogen; MIP: Major intrinsic protein family; BOR: Borate transporter family; NIP: Nodulin-26-like intrinsic protein family; GFP: Green fluorescent protein; CFP: Cyan fluorescent protein; CaMV: 35 S cauliflower mosaic virus 355 RNA

\section{Acknowledgements}

The authors greatly thank Dr. Manuel Gonzalez-Guerrero for his support helping to conceive and plan the experiments. We thank Dr. Toru Fujiwara (University of Tokyo, Japan), Dr. Junpei Takano (Osaka Prefecture University, Japan) and Dr. Kyoko Miwa (Hokkaido University, Japan) for providing the A. thaliana nip5;1-1 mutant seeds used in this study. We also thank Inmaculada Rivas Ramírez and the Elemental Analysis Unit at the Interdepartmental Investigation Service (SIdl)-UAM for their technical assistance ensuring that the ICP-MS analyses were performed on time. The authors declare no conflict of interest.

\section{Authors' contributions}

M.R. conceived and planned the experiments. M.R. and S.G.R. carried out the experiments. M.R. and S.G.R. contributed to the interpretation of the results. M.R. took the lead in writing the manuscript with S.G.R. and L.B. contribution. All authors provided critical feedback and helped shape the research, analysis, and manuscript. All authors have read and approved the manuscript.

\section{Funding}

The author(s) received no specific funding for this work.

\section{Availability of data and materials}

All data generated or analyzed during this study are included in this published article (and its additional files). Nonetheless, the datasets used and/or analysed during the current study are available from the corresponding author on reasonable request.

Ethics approval and consent to participate

Not applicable.

\section{Consent for publication}

Not applicable.

\section{Competing interests}

The authors declare that they have no competing interests.

Received: 15 June 2020 Accepted: 22 November 2020

Published online: 09 December 2020

References

1. The WK. Effect of Boric Acid and Borax on the Broad Bean and certain other Plants. Ann Bot. Oxford University Press. 1923;37:629-72.

2. O'Neill MA, Eberhard S, Albersheim P, Darvill AG. Requirement of borate cross-linking of Cell Wall Rhamnogalacturonan II for Arabidopsis growth Science. 2001;294(5543):846-9.

3. Koshiba T, Kobayashi M, Matoh T. Boron deficiency: how does the defect in cell wall damage the cells? Plant Signal Behav. 2009;4(6):557-8.

4. Brown PH, Bellaloui N, Wimmer MA, Bassil ES, Ruiz J, Hu H, et al. Boron in plant biology. Plant Biol. 2002;4(2):205-23.

5. Shireen F, Nawaz MA, Chen C, Zhang Q, Zheng Z, Sohail H, et al. Boron: functions and approaches to enhance its availability in plants for sustainable agriculture. Int J Mol Sci. 2018;19(7):1856.

6. Marschner P. Marschner 's mineral nutrition of higher plants. Orford: Elsevier; 2012. p. 1-651.

7. Yoshinari A, Takano J. Insights into the mechanisms underlying boron homeostasis in plants. Front Plant Sci. 2017;8:1951. 
8. Reid R. Understanding the boron transport network in plants. Plant Soil. 2014;385(1-2):1-13.

9. Miwa K, Tanaka M, Kamiya T, Fujiwara T. Molecular Mechanisms of Boron Transport in Plants: Involvement of Arabidopsis NIP5;1 and NIP6;1. In: MIPs and their Role in the Exchange of Metalloids. New York: Springer; 2010. p. 83-96.

10. Raven JA. Short- and long-distance transport of boric acid in plants. New Phytol. 1980;84(2):231-49.

11. Wallace IS, Choi W-G, Roberts DM. The structure, function and regulation of the nodulin 26-like intrinsic protein family of plant aquaglyceroporins. Biochim Biophys Acta (BBA)-Biomembranes. 2006;1758(8):1165-75.

12. Fitzpatrick KL, Reid RJ. The involvement of aquaglyceroporins in transport of boron in barley roots. Plant Cell Environ. 2009;32(10):1357-65.

13. Bhattacharjee H, Mukhopadhyay R, Thiyagarajan S, Rosen BP. Aquaglyceroporins: ancient channels for metalloids. J Biol. 2008;7(9):1-6.

14. Tanaka M, Wallace IS, Takano J, Roberts DM, Fujiwara T. NIP6;1 is a boric Acid Channel for preferential transport of boron to growing shoot tissues in Arabidopsis. Plant Cell. 2008:20(10):2860-75.

15. Takano J, Wada M, Ludewig U, Schaaf G, von Wirén N, Fujiwara T. The Arabidopsis major intrinsic protein NIP5;1 is essential for efficient boron uptake and plant development under boron limitation. Plant Cell. 2006; 18(6):1498-509.

16. Bienert MD, Bienert GP. Plant Aquaporins and Metalloids. In: Plant aquaporins. Cham: Springer; 2017. p. 297-332.

17. Takano J, Tanaka M, Toyoda A, Miwa K, Kasai K, Fuji K, et al. Polar localization and degradation of Arabidopsis boron transporters through distinct trafficking pathways. Proc Natl Acad Sci. 2010;107(11):5220-5.

18. Takano J, Noguchi K, Yasumori M, Kobayashi M, Gajdos Z, Miwa K, et al. Arabidopsis boron transporter for xylem loading. Nature. 2002:420(6913):337-40.

19. Takano J, Miwa K, Fujiwara T. Boron transport mechanisms: collaboration of channels and transporters. Vol. 13, Trends in Plant Science. Elsevier; 2008. p. 451-457.

20. Miwa K, Fujiwara T. Boron transport in plants: co-ordinated regulation of transporters. Ann Bot. 2010;105(7):1103-8.

21. Varshney RK, Close TJ, Singh NK, Hoisington DA, Cook DR. Orphan legume crops enter the genomics era! Curr Opin Plant Biol. 2009;12(2):202-10.

22. Brewin NJ. Development of the legume root nodule. Annu Rev Cell Biol. 1991;7:191-226.

23. Patriarca $\mathrm{E}$, Tatè $\mathrm{R}$, laccarino $\mathrm{M}$. Key role of bacterial $\mathrm{NH} 4+$ metabolism in rhizobium-plant Symbiosis. Microbiol Mol Biol Rev. 2002;66(2):203-22.

24. Jones KM, Kobayashi H, Davies BW, Taga ME, Walker GC. How rhizobia symbionts invade plants: The Sinorhizobium - Medicago model. Nat Rev Microbiol. 2007;5(8):619-33.

25. Boyle E. Oceans: Nitrogen pollution knows no bounds. Science. 2017; 356(63399):700-1.

26. Kanter DR. Nitrogen pollution: a key building block for addressing climate change. Clim Chang. 2018;147(1-2):11-21.

27. Dent $\mathrm{D}$, Cocking E. Establishing symbiotic nitrogen fixation in cereals and other non-legume crops: The Greener Nitrogen Revolution Agriculture and Food Security 2017:6(1):1-9.

28. Pankievicz VCS, Irving TB, Maia LGS, Ané JM. Are we there yet? The long walk towards the development of efficient symbiotic associations between nitrogen-fixing bacteria and non-leguminous crops. BMC Biol. 2019;17(1):99.

29. White J, Prell J, James EK, Poole P. Nutrient sharing between symbionts. Plant Physiol. 2007;144(2):604-14.

30. Bolaños $L$, Brewin $N J$, Bonilla I. Effects of boron on rhizobium-legume cell-surface interactions and nodule development. Plant Physiol. 1996;1 10(4):1249-56.

31. Redondo-Nieto M, Pulido L, Reguera M, Bonilla I, Bolaños L. Developmentally regulated membrane glycoproteins sharing antigenicity with rhamnogalacturonan II are not detected in nodulated boron deficient Pisum sativum. Plant Cell Environ. 2007;30(11):1436-43.

32. Reguera $\mathrm{M}$, Bonilla I, Bolaños L. Boron deficiency results in induction of pathogenesis-related proteins from the PR-10 family during the legumerhizobia interaction. J Plant Physiol. 2010;167(8):625-32.

33. Reguera M, Abreu I, Brewin NJ, Bonilla I, Bolaños L. Borate promotes the formation of a complex between legume AGP-extensin and Rhamnogalacturonan II and enhances production of rhizobium capsular polysaccharide during infection thread development in Pisum sativum symbiotic root nodules. Plant Cell Environ. 2010;33(12):2112-20.

34. Reguera M, Wimmer M, Bustos P, Goldbach HE, Bolaños L, Bonilla I. Ligands of boron in Pisum sativum nodules are involved in regulation of oxygen concentration and rhizobial infection. Plant Cell Environ. 2010;33(6):1039-48.
35. Reguera M, Espí A, Bolaños L, Bonilla I, Redondo-Nieto M. Endoreduplication before cell differentiation fails in boron-deficient legume nodules. Is boron involved in signalling during cell cycle regulation?: Letter. New Phytol. 2009; 183(1):8-12.

36. Min X, Wu H, Zhang Z, Wei X, Jin X, Ndayambaza B, et al. Genome-wide identification and characterization of the aquaporin gene family in Medicago truncatula. J Plant Biochem Biotechnol. 2019;28(3):320-35.

37. Bogacki P, Peck DM, Nair RM, Howie J, Oldach KH. Genetic analysis of tolerance to boron toxicity in the legume Medicago truncatula. BMC Plant Biol. 2013;13(1):54.

38. Takata K, Matsuzaki T, Tajika Y. Aquaporins: water channel proteins of the cell membrane. Prog Histochem Cytochem. 2004;39(1):1-83.

39. Hussain A, Tanveer R, Mustafa G, Faroog M, Amin I, Mansoor S. Comparative phylogenetic analysis of aquaporins provides insight into the gene family expansion and evolution in plants and their role in drought tolerant and susceptible chickpea cultivars. Genomics. 2020;112(1):263-75.

40. Hove RM, Bhave M. Plant aquaporins with non-aqua functions: deciphering the signature sequences. Plant Mol Biol. 2011;75(4-5):413-30.

41. Symbimics. https://iant.toulouse.inra.fr/symbimics/ Accessed 20 March 2018.

42. Medicago truncatula Gene Expression Atlas. Noble Research Institute. https:// mtgea.noble.org/v3/ Accessed 20 March 2018.

43. Mattos D, Hippler FWR, Boaretto RM, Stuchi ES, Quaggio JA. Soil boron fertilization: The role of nutrient sources and rootstocks in citrus production. J Integr Agric. 2017;16(7):1609-16.

44. Wang Y, Shi L, Cao X, Xu F. Boron nutrition and boron application in crops. In: Advances in Plant and Animal Boron Nutrition: Springer Netherlands; 2007. p. 93-101.

45. Noguchi K, Yasumori M, Imai T, Naito S, Matsunaga T, Oda H, et al. bor1-1, an Arabidopsis thaliana mutant that requires a high level of boron. Plant Physiol. 1997;115(3):901-6.

46. Pang Y, Li L, Ren F, Lu P, Wei P, Cai J, et al. Overexpression of the tonoplast aquaporin AtTIP5;1 conferred tolerance to boron toxicity in Arabidopsis. J Genet Genomics. 2010;37(6):389-97.

47. Martinez-Ballesta MDC, Bastías E, Zhu C, Schäffner AR, González-Moro B, González-Murua C, et al. Boric acid and salinity effects on maize roots. Response of aquaporins ZmPIP1 and ZmPIP2, and plasma membrane H+ATPase, in relation to water and nutrient uptake. Physiol Plant. 2008;132(4): 479-90.

48. Kumar K, Mosa KA, Chhikara S, Musante C, White JC, Dhankher OP. Two rice plasma membrane intrinsic proteins, OsPIP2;4 and OsPIP2;7, are involved in transport and providing tolerance to boron toxicity. Planta. 2014;239(1):187-98.

49. Cook DR. Medicago truncatula - a model in the making! Curr Opin Plant Biol. 1999;2(4):301-4

50. Tanaka M, Takano J, Chiba Y, Lombardo F, Ogasawara Y, Onouchi H, et al. Boron-dependent degradation of NIP5;1 mRNA for acclimation to excess boron conditions in Arabidopsis. Plant Cell. 2011;23(9):3547-59.

51. Murata K, Mitsuoka K, Hiral T, Walz T, Agre P, Heymann JB, et al. Structural determinants of water permeation through aquaporin-1. Nature. 2000; 407(6804):599-605.

52. Wu B, Beitz E. Aquaporins with selectivity for unconventional permeants. Cell Mol Life Sci. 2007;64:2413-21.

53. Bansal A, Sankararamakrishnan R. Homology modeling of major intrinsic proteins in rice, maize and Arabidopsis: comparative analysis of transmembrane helix association and aromatic/arginine selectivity filters. BMC Struct Biol. 2007;7(1):27.

54. Kamiya T, Fujiwara T. Arabidopsis NIP1;1 transports antimonite and determines antimonite sensitivity. Plant Cell Physiol. 2009;50(11):1977-81.

55. Bolaños L, Esteban E, de Lorenzo C, Fernandez-Pascual M, de Felipe MR, Garate A, et al. Essentiality of boron for symbiotic dinitrogen fixation in pea (Pisum sativum) rhizobium nodules. Plant Physiol. 1994;104(1):85-90.

56. Tejada-Jiménez M, Castro-Rodríguez R, Kryvoruchko I, Mercedes Lucas M, Udvardi M, Imperial J, et al. Medicago truncatula natural resistanceassociated macrophage Protein 1 is required for iron uptake by rhizobiainfected nodule cells. Plant Physiol. 2015;168(1):258-72.

57. Brito B, Palacios JM, Hidalgo E, Imperial J, Ruiz-Argueso T. Nickel availability to pea (Pisum sativum L.) plants limits hydrogenase activity of rhizobium leguminosarum bv. Viciae bacteroids by affecting the processing of the hydrogenase structural subunits. J Bacteriol. 1994;176(17):5297-303.

58. Kato Y, Miwa K, Takano J, Wada M, Fujiwara T. Highly boron deficiencytolerant plants generated by enhanced expression of NIP5;1, a boric acid channel. Plant Cell Physiol. 2009;50(1):58-66. 
59. Murashige T, Skoog F. A revised medium for rapid growth and bio assays with tobacco tissue cultures. Physiol Plant. 1962;15(3):473-97.

60. Kazmierczak T, Nagymihaly M, Lamouche F, Barriére Q, Guefrachi I, Alunni B, et al. Specific host-responsive associations between medicago truncatula accessions and sinorhizobium strains. Mol Plant-Microbe Interact. 2017;30(5): 399-409.

61. Hardy RWF, Holsten RD, Jackson EK, Burns RC. The acetylene - ethylene assay for N2 fixation: laboratory and field evaluation. Plant Physiol. 1968;43: 1185-207.

62. TAIR. The Arabidopsis Information Resource. https://www.arabidopsis.org/ Accessed 20 November 2017.

63. Phytozome v12.1. The Plant Genomics Resource. JGl. https://phytozome.jgi. doe.gov/pz/portal.htmlAccessed 20 November 2017.

64. Kakar K, Wandrey M, Czechowski T, Gaertner T, Scheible WR, Stitt M, et al. A community resource for high-throughput quantitative RT-PCR analysis of transcription factor gene expression in Medicago truncatula. Plant Methods. 2008;4(1):18.

65. Boisson-Dernier A, Chabaud M, Garcia F, Bécard G, Rosenberg C, Barker DG. Agrobacterium rhizogenes-transformed roots of Medicago truncatula for the study of nitrogen-fixing and endomycorrhizal symbiotic associations. Mol Plant-Microbe Interact. 2001;14(6):695-700.

66. Vincent JM. A manual for the practical study of the root-nodule bacteria. London: IBP Handbk 15 Oxford and Edinburgh: Blackwell Scientific Publications; 1970. p. 164.

67. Nakagawa T, Ishiguro S, Kimura T. Gateway vectors for plant transformation. Plant Biotechnol. 2009:26(3):275-84

68. Vernoud V, Journet EP, Barker DG. MtENOD20, a nod factor-inducible molecular marker for root cortical cell activation. Mol Plant-Microbe Interact. 1999;12(7):604-14.

69. Ashby AM, Watson MD, Loake GJ, Shaw CH. Ti plasmid-specified chemotaxis of agrobacterium tumefaciens $\mathrm{C} 58 \mathrm{C} 1$ toward vir-inducing phenolic compounds and soluble factors from monocotyledonous and dicotyledonous plants. J Bacteriol. 1988;170(9):4181-7.

70. Yang K, Rong W, Qi L, Li J, Wei X, Zhang Z. Isolation and characterization of a novel wheat cysteine-rich receptor-like kinase gene induced by Rhizoctonia cerealis. Sci Rep. 2013;3(1):1-10.

71. Voinnet O, Rivas S, Mestre P, Baulcombe D. An enhanced transient expression system in plants based on suppression of gene silencing by the p19 protein of tomato bushy stunt virus. Plant J. 2003:33(5):949-56.

72. Sparkes IA, Runions J, Kearns A, Hawes C. Rapid, transient expression of fluorescent fusion proteins in tobacco plants and generation of stably transformed plants. Nat Protoc. 2006; 1 (4):2019-25.

73. UniProt. Elixir. http://www.uniprot.org/ Accessed 9 April 2018.

74. I-TASSER. Protein structure \& function predictions. Zhang Lab. https:// zhanglab.ccmb.med.umich.edu/l-TASSER/ Accessed 16 April 2018.

75. Zhang X, Henriques R, Lin SS, Niu QW, Chua NH. Agrobacterium-mediated transformation of Arabidopsis thaliana using the floral dip method. Nat Protoc. 2006; (2):641-6.

76. ImageJ. Image Processing and Analysis in Java. http://rsbweb.nih.gov/ij/.

77. Gómez-Soto D, Galván S, Rosales E, Bienert P, Abreu I, Bonilla I, et al. Insights into the role of phytohormones regulating pAtNIP5;1 activity and boron transport in Arabidopsis thaliana. Plant Sci. 2019;287:110198.

78. Reguera M, Conesa CM, Gil-Gómez A, Haros CM, Pérez-Casas MÁ, BrionesLabarca $V$, et al. The impact of different agroecological conditions on the nutritional composition of quinoa seeds. PeerJ. 2018;6:e4442.

\section{Publisher's Note}

Springer Nature remains neutral with regard to jurisdictional claims in published maps and institutional affiliations.

Ready to submit your research? Choose BMC and benefit from:
- fast, convenient online submission
- thorough peer review by experienced researchers in your field
- rapid publication on acceptance
- support for research data, including large and complex data types
- gold Open Access which fosters wider collaboration and increased citations
- maximum visibility for your research: over 100M website views per year
At BMC, research is always in progress.
Learn more biomedcentral.com/submissions

